\title{
ANÁLISE DO DESEMPENHO DAS EXPORTAÇÕES BRASILEIRAS DE CARNE BOVINA: UMA APLICAÇÃO DO MÉTODO CONSTANT-MARKET-SHARE, 1995-2003
}

\author{
Lenilma Vera Nunes Machado \\ Mário Miguel Amin ${ }^{2}$ \\ Fátima Marília Andrade de Carvalho \\ Antônio Cordeiro de Santana ${ }^{4}$
}

Resumo - Este trabalho analisa o desempenho das exportações brasileiras de carne bovina, no período de 1995 a 2003. Mostra que o incremento significativo das exportações tornou o país o maior exportador do produto, de forma que se procura identificar os fatores que contribuíram para esse crescimento. Verifica-se o comportamento das exportações brasileiras de carne bovina in natura. Os procedimentos metodológicos envolveram a aplicação do modelo Constant-Market-Share para decompor as fontes de crescimento das exportações nos efeitos crescimento do comércio mundial, composição da pauta, destino das exportações e competitividade. O efeito composição da pauta não pôde ser estimado, uma vez que o modelo foi aplicado apenas a um produto. Os resultados mostram que os efeitos competitividade e estruturais impulsionaram as exportações brasileiras. Conclui-se que o Brasil aumentou a sua parcela de participação no mercado mundial graças a um conjunto de fatores que possibilitou o aumento das suas vendas por meio da conquista de novos mercados.

Palavras-chave: Carne bovina - Brasil, exportações, Constant-Market-Share.

\section{Introdução}

O Brasil é o maior exportador de carne bovina, com participação em torno de $25 \%$ no mercado mundial. Em 2004, o país vendeu para o mercado externo 1,6 milhão de toneladas, uma receita da ordem de US\$

\footnotetext{
Mestre em Economia pela Universidade da Amazônia. E-mail: lenilmachado@hotmail.com

Professor Titular da Universidade da Amazônia. E-mail: maramin@amazon.com.br

3 Professora Adjunta do Departamento de Economia Rural da Universidade Federal de Viçosa. E-mail: fmac@ufv.br

4 Professor Titular da Universidade Federal Rural da Amazônia. E-mail: santana@nautilus.com.br
} 
2,4 bilhões, conforme dados do Anuário da Pecuária Brasileira (Anualpec). Cabe destacar que o volume exportado teve um incremento de $471 \%$, em relação a 1995, ano em que foram comercializadas 280 mil toneladas. As melhorias introduzidas na pecuária de corte, por meio dos investimentos em novas tecnologias associadas às vantagens de recursos naturais, permitiram elevar a produção para atender à demanda externa crescente de carne bovina brasileira.

A ocorrência de enfermidades no rebanho de outros países exportadores favoreceu as exportações brasileiras de carne bovina. A certificação do Brasil, como área livre de aftosa com vacinação nos circuitos pecuários Sul, Leste e Centro-Oeste, aumentou as oportunidades de negócio do país. Além da sanidade do rebanho, outros fatores alavancaram as exportações de carne, como a desvalorização do câmbio e as ações de marketing e promoção do produto no mercado externo.

O aumento nas exportações resulta em ganhos para o país, os quais, por si só, não determinam que este seja competitivo em dado setor. Assim, é necessário verificar os fatores que influenciaram o comportamento das exportações, para verificar se o país tem sido competitivo no mercado internacional.

Este trabalho objetivou verificar se o Brasil obteve ganhos de competitividade, em razão do aumento nas vendas externas de carne bovina. Dessa forma, procurou-se analisar o comportamento das exportações desse produto e identificar os fatores determinantes do seu crescimento, por meio da aplicação do método Constant-Market-Share (CMS), no período de 1995 a 2003.

O artigo está estruturado em quatro seções, incluindo esta introdução. Na segunda seção, analisa-se a dinâmica comportamental do mercado internacional de carne bovina; na terceira, é apresentada a metodologia e descrito o método CMS, que permite decompor as fontes de crescimento das exportações; na quarta, os resultados obtidos são analisados e discutidos e, finalmente, são apresentadas algumas considerações sobre o estudo. 
Lenilma Vera Nunes Machado, Mário Miguel Amin,

Fátima Marília Andrade de Carvalho \& Antônio Cordeiro de Santana

\section{Mercado internacional de carne bovina}

A produção mundial de carne bovina ficou em torno de 51 milhões de toneladas, em 2004, conforme estimativas do Departamento de Agricultura dos Estados Unidos (USDA), e concentrou-se em cinco grandes centros - Estados Unidos, União Européia, Brasil, China e Argentina - que participaram com cerca de $70 \%$ da oferta global. Os Estados Unidos foram o maior produtor mundial, enquanto o Brasil e a China ocuparam, respectivamente, a segunda e a terceira posição.

O volume de carne produzido na China aumentou, em média, $12,7 \%$ ao ano, no período 1990-2004, impulsionado pelo crescimento da demanda interna, em virtude da elevação da renda e da rápida urbanização. ${ }^{5} \mathrm{~A}$ produção do Brasil cresceu, em média, 3,4\% ao ano, no período citado. $\mathrm{O}$ aumento na oferta tem possibilitado abastecer o mercado doméstico, reduzindo a dependência das importações para complementar o abastecimento interno, bem como gerar excedentes exportáveis. Esse crescimento se deve a fatores como investimentos em novas tecnologias da genética, sanidade, manejo, gerenciamento e nutrição. ${ }^{6}$

As condições climáticas desfavoráveis à atividade pecuária na Austrália e a liquidação de matrizes nos Estados Unidos ${ }^{7}$ contribuíram para o baixo crescimento da oferta de carne nesses países. Na União Européia, a reforma na Política Comum Agrícola, na década de 90, e a ocorrência de Encefalopatia Espongiforme Bovina (BSE, na sigla em inglês), conhecida como mal da vaca louca, contribuíram para reduzir a produção de carne.

Em 2004, o Brasil possuía o maior rebanho comercial do mundo, cerca de 171 milhões de cabeças, conforme dados do Anualpec. O crescimento do efetivo de bovinos, de 1996 a 2003, foi sustentado por um ciclo de alta na pecuária, em virtude da retenção de bezerros durante esses sete anos,

WORLD beef \& cattle trade: evolving e expanding. Economic Research Service, Agricultural Outlook, dec. 1997. Disponível em: 〈www.usda.gov.br〉. Acesso em: maio 2004.

6 Sabella, J. Boi verde 'made in Brasil'. Agroanalysis, Rio de Janeiro, v. 24, n. 11, p. 28-29, nov. 2004.

7 De acordo com Mustefaga (2003), a seca atingiu praticamente toda a metade oeste dos Estados Unidos e afetou cerca de $40 \%$ do rebanho de vacas de corte. 
em torno de 1,5 milhão de matrizes ao ano, e da explosão das exportações. Todavia, o rebanho reduziu-se em 6 milhões de cabeças em 2004, devido ao aumento no abate de matrizes, em decorrência da desvalorização do preço dos bezerros que reduziu a rentabilidade da cria, em relação a outras atividades. ${ }^{8}$

Fatores tradicionais, como disponibilidade de terras a preços baixos ${ }^{9} \mathrm{e}$ de pastagens para alimentação do gado, permitiram expandir o rebanho para atender à demanda mundial crescente do produto brasileiro. Porém, mais importante que estes fatores foram os investimentos em tecnologia, que permitiram melhorar os índices da pecuária de corte, conforme mostra o Quadro 1.

Quadro 1 - Evolução dos índices da pecuária de corte do Brasil

\begin{tabular}{lccc}
\hline \multicolumn{1}{c}{ Índices } & $\mathbf{1 9 9 4}$ & $\mathbf{2 0 0 4}$ & Variações \% \\
\hline Natalidade \% & 50 & 60 & 20 \\
Mortalidade até a desmama \% & 10 & 8 & -20 \\
Idade da primeira cria - anos & 5 & 4 & -20 \\
Abates - anos & 5 & 3,5 & -30 \\
Lotação - UA/ha & 0,5 & 0,7 & 40 \\
Desfrute \% & 16,5 & 21 & 27 \\
\hline
\end{tabular}

Fonte: Scot Consultoria apud Torres Júnior et al. (2005b, p.41).

As exportações mundiais de carne bovina evoluíram de 5,4 milhões de toneladas, em 1995, para 6,6 milhões de toneladas, em 2004, de acordo com dados apresentados na Tabela 1. Destacam-se como maiores exportadores Austrália, Argentina, Brasil, Estados Unidos, Nova Zelândia e União Européia.

Nehmi Filho, V. C. Para onde caminha a pecuária brasileira. Anualpec, São Paulo, p. 14-23, 2005.

9 De acordo com Gasques e Bastos (2005), o preço médio do hectare em terras de pastagens no Brasil, em 2003, foi de US\$ 567, enquanto nos Estados Unidos foi de US\$1,495. 
Lenilma Vera Nunes Machado, Mário Miguel Amin,

Fátima Marília Andrade de Carvalho \& Antonio Cordeiro de Santana

Tabela 1 -Exportações mundiais de carne bovina em milhares de toneladas - 1995-2005

\begin{tabular}{lrrrrrrrrrrr}
\hline \multicolumn{1}{c}{ País / Região } & $\mathbf{1 9 9 5}$ & $\mathbf{1 9 9 6}$ & $\mathbf{1 9 9 7}$ & $\mathbf{1 9 9 8}$ & $\mathbf{1 9 9 9}$ & $\mathbf{2 0 0 0}$ & $\mathbf{2 0 0 1}$ & $\mathbf{2 0 0 2}$ & $\mathbf{2 0 0 3}$ & $\mathbf{2 0 0 4}$ & $\mathbf{2 0 0 5}^{*}$ \\
\hline Argentina & 535 & 496 & 458 & 303 & 359 & 357 & 169 & 348 & 386 & 617 & 700 \\
\hline Austrália & 1.109 & 1.026 & 1.184 & 1268 & 1.270 & 1.338 & 1.399 & 1.366 & 1.264 & 1.395 & 1.400 \\
\hline Brasil & 228 & 224 & 232 & 306 & 464 & 492 & 748 & 881 & 1.175 & 1.628 & 1.850 \\
\hline Canadá & 245 & 319 & 382 & 427 & 491 & 523 & 574 & 610 & 384 & 559 & 625 \\
\hline Estados Unidos & 826 & 851 & 969 & 985 & 1.094 & 1.119 & 1.029 & 1.110 & 1.143 & 209 & 290 \\
\hline Nova Zelândia & 497 & 520 & 530 & 509 & 462 & 505 & 516 & 505 & 578 & 606 & 565 \\
\hline União Européia & 1.199 & 1.101 & 1.092 & 780 & 994 & 644 & 575 & 512 & 400 & 360 & 300 \\
\hline Uruguai & 149 & 192 & 251 & 218 & 189 & 236 & 145 & 259 & 320 & 400 & 440 \\
\hline Outros & 665 & 711 & 707 & 661 & 1.560 & 1.333 & 1.254 & 1.381 & 1187 & 824 & 829 \\
\hline Total & $\mathbf{5 . 4 5 3}$ & $\mathbf{5 . 4 4 0}$ & $\mathbf{5 . 8 0 5}$ & $\mathbf{5 4 5 7}$ & $\mathbf{6 . 8 8 3}$ & $\mathbf{6 . 5 4 7}$ & $\mathbf{6 . 4 0 9}$ & $\mathbf{6 . 9 7 2}$ & $\mathbf{6 . 8 3 7}$ & $\mathbf{6 . 5 9 8}$ & $\mathbf{6 . 9 9 9}$ \\
\hline
\end{tabular}

*Previsão.

Fonte: United States Department of Agriculture (1995-2005).

O Brasil tornou-se o terceiro maior exportador em 2001, atrás dos Estados Unidos e da Austrália, e assumiu a liderança no mercado internacional em 2004, tendo exportado 1,6 milhão de toneladas. A previsão para 2005 é que o país venha a exportar 1,9 milhão de toneladas. A Austrália permaneceu na segunda posição, e a estimativa é que exporte 1,4 milhão de toneladas em 2005. A Argentina apresentou o nível mais de exportações em 2001, devido à ocorrência de casos da febre aftosa, que reduziu o volume exportado em cerca de $50 \%$. O país tornou-se o terceiro exportador em 2004, com retomada das vendas para o mercado europeu e conquista de novos mercados, e estima-se que ela venha a exportar 700 mil toneladas de carne em 2005.

O anúncio de um caso de BSE nos Estados Unidos, no final de 2003, reduziu as exportações do país em torno de um milhão de toneladas no ano seguinte. A previsão é de que sejam exportadas 290 mil toneladas em 2005, volume $75 \%$ inferior ao de 2003 , enquanto as exportações do Canadá e do Uruguai devem alcançar 625 mil e 440 mil toneladas, respectivamente. A estimativa para a Nova Zelândia é de queda nas exportações, em decorrência da elevação do abate de matrizes em 2004, para atender ao aumento na demanda externa. As exportações da União Européia vêm caindo, devido às mudanças nas políticas agrícolas e dos casos de BSE que afetaram a produção de carne. 
As barreiras não-tarifárias têm ganhado importância como fator de restrição ao fluxo do comércio internacional. No mercado mundial de carne bovina destacam-se as barreiras sanitárias, que restringem a comercialização da carne in natura. $\mathrm{O}$ registro de focos de febre aftosa e de vaca louca tem trazido prejuízos aos países exportadores, dada a suspensão parcial ou total das compras pelos países importadores, preocupados com a segurança alimentar.

Os países totalmente livres de febre aftosa e sem vacinação, como Austrália, Estados Unidos e Canadá, têm obtido preços mais elevados no mercado internacional, devido à preferência dos grandes importadores por carne desses países. Esta limitação contribui para que o preço pago pela carne bovina do Brasil seja menor do que o alcançado por esses países. A tendência é de alta dos preços internacionais do produto, cujo aumento poderia ter sido maior em 2004, se não fosse o grande abate de matrizes no Brasil, na Argentina e no Uruguai, o que permitiu atender ao crescimento das importações mundiais (Nehmi Filho, 2005).

O Gráfico 1 mostra a evolução das exportações brasileiras de carne bovina. Observa-se que, até 2000, a carne industrializada representava o maior peso nas exportações, porém a carne in natura passou a predominar a partir de 2001. Os baixos preços no mercado internacional e a garantia de sanidade do rebanho brasileiro favoreceram o crescimento das vendas de carne in natura. As exportações de carne industrializada também cresceram, porém em ritmo menos acelerado do que as de carne in natura. 


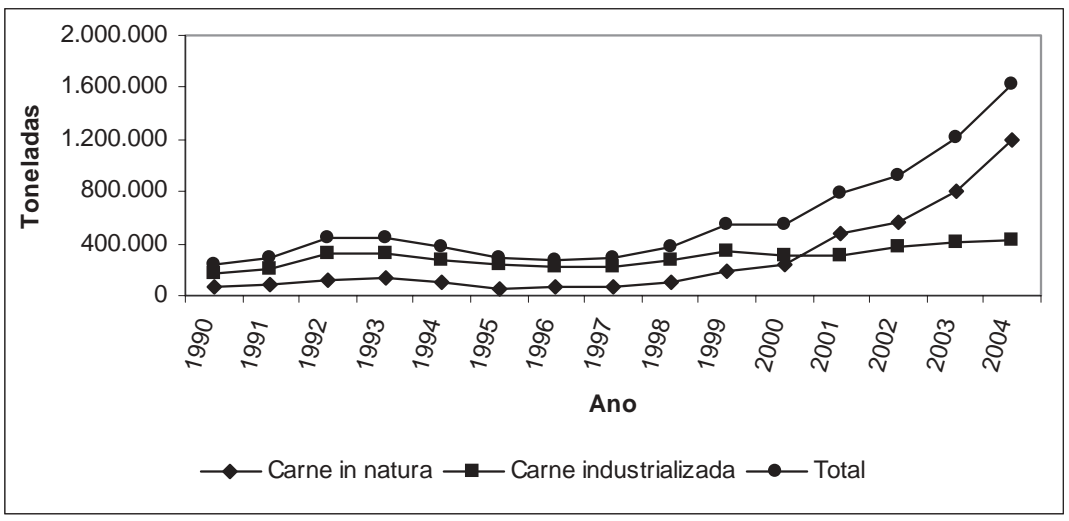

Gráfico 1: Exportações brasileiras de carne bovina em equivalentecarcaça.

Fonte: Ministério do Desenvolvimento e Comércio Exterior (1990-1992); Anuário da Pecuária Brasileira (1998-2005).

Em 2004, o Brasil exportou cerca de $20 \%$ da produção de carne bovina, e sua exportação de carne in natura (em toneladas) foi de $85 \%$ e de carne industrializada, $15 \%$. Os principais destinos da carne in natura, em volume, são Rússia (154 mil toneladas), Chile (112 mil toneladas), Reino Unido (87 mil toneladas) e Egito (86 mil toneladas), conforme o Anualpec (2005), enquanto o da industrializada são os Estados Unidos e o Reino Unido. Há uma concentração das exportações para esses países, que, juntos, participaram com $67 \%$ do volume exportado pelo Brasil em 2004, com receita de US\$240,4 milhões, de acordo com o Anualpec (2005).

Os esforços empreendidos pelo governo no combate à febre aftosa, por meio de ampla campanha de vacinação na década de 90 , foi fundamental para que o Brasil fosse considerado pela Organização Mundial de Saúde Animal (OIE) como área livre de aftosa com vacinação, nos circuitos pecuários Sul, Leste e Centro-Oeste. Desta forma, o país pôde ampliar suas oportunidades de vendas de carne bovina para o mercado externo. 
A desvalorização cambial de 1999 contribuiu para induzir ao aumento das exportações brasileiras de carne bovina, ao reduzir o preço do produto em dólares e torná-lo mais competitivo no mercado internacional..$^{10}$ Porém, a desvalorização da taxa de câmbio não atuou, de forma isolada, para impulsionar as vendas, de forma que há outros fatores a serem considerados, como os avanços tecnológicos na pecuária de corte e a sanidade do rebanho.

Os Estados Unidos são os maiores importadores de carne bovina, seguidos por Japão, Rússia, Coréia do Sul, Canadá e México. Alguns desses países são grandes produtores e exportadores de carne, enquanto outros não são auto-suficientes para atender à demanda interna. Segundo Dyck e Nelson (2003), os países do Leste Asiático são grandes importadores de carne, uma vez que a densidade demográfica e a limitação de terras disponíveis para agricultura, devido a fatores geográficos, tornam o custo de produção de alimentos relativamente mais elevado.

A Tabela 2 mostra as importações mundiais de carne bovina, em toneladas. Os Estados Unidos importaram 1,6 milhão de toneladas em 2004, um aumento de $22 \%$ em relação a 2003 . Com o estoque de bovinos a níveis baixos, este país aumentou as compras de carne do Canadá e do Uruguai, para atender à demanda doméstica robusta.

10 O estudo de Margarido (2001) mostra que a desvalorização do câmbio de 1999 não trouxe crescimento acelerado das exportações, como era esperado. O autor alerta que a questão cambial não deve ser vista isoladamente, mas que seja analisada a conjuntura internacional, isto é, verificar se os principais países demandantes de commodities estão num ciclo de crescimento econômico. 
Lenilma Vera Nunes Machado, Mário Miguel Amin,

Fátima Marília Andrade de Carvalho \& Antônio Cordeiro de Santana

Tabela 2 - Importações mundiais de carne bovina, em milhares de toneladas - 1995-2005

\begin{tabular}{lrrrrrrrrrrr}
\hline \multicolumn{1}{c}{ País/Região } & $\mathbf{1 9 9 5}$ & $\mathbf{1 9 9 6}$ & $\mathbf{1 9 9 7}$ & $\mathbf{1 9 9 8}$ & $\mathbf{1 9 9 9}$ & $\mathbf{2 0 0 0}$ & $\mathbf{2 0 0 1}$ & $\mathbf{2 0 0 2}$ & $\mathbf{2 0 0 3}$ & $\mathbf{2 0 0 4}$ & $\mathbf{2 0 0 5 *}$ \\
\hline Canadá & 245 & 228 & 244 & 232 & 254 & 263 & 300 & 308 & 274 & 111 & 100 \\
\hline Coréia do Sul & 229 & 221 & 226 & 125 & 242 & 324 & 246 & 430 & 444 & 218 & 230 \\
\hline Estados Unidos & 954 & 940 & 1.063 & 1.199 & 1.303 & 1.375 & 1.435 & 1.460 & 1.363 & 1.669 & 1.696 \\
\hline Japão & 922 & 933 & 954 & 989 & 1.007 & 1.067 & 1.002 & 712 & 810 & 617 & 625 \\
\hline México & 58 & 105 & 203 & 307 & 358 & 420 & 426 & 489 & 370 & 287 & 320 \\
\hline Rússia & 612 & 876 & 1.047 & 770 & 784 & 415 & 648 & 719 & 720 & 730 & 750 \\
\hline União Européia & 422 & 395 & 459 & 414 & 457 & 450 & 413 & 518 & 550 & 560 & 550 \\
\hline Outros & 815 & 826 & 834 & 758 & 1.146 & 1.114 & 920 & 1.127 & 1.083 & 1.127 & 697 \\
\hline Total & $\mathbf{4 . 2 5 7}$ & $\mathbf{4 . 5 2 4}$ & $\mathbf{5 . 0 3 0}$ & $\mathbf{4 7 9 4}$ & $\mathbf{5 . 5 5 1}$ & $\mathbf{5 . 4 2 8}$ & $\mathbf{5 . 3 9 0}$ & $\mathbf{5 . 7 6 3}$ & $\mathbf{5 . 6 1 4}$ & $\mathbf{5 . 3 1 9}$ & $\mathbf{4 . 9 1 8}$ \\
\hline
\end{tabular}

*Previsão.

Fonte: United States Department of Agriculture (1990-2005).

As importações do Japão, segundo maior importador, vêm decrescendo desde 2001, devido à ocorrência de diversos casos de vacas infectadas por BSE. O Japão suspendeu as importações de carne dos Estados Unidos em 2004, após o anúncio de um caso de vaca louca no país. Na Rússia, a redução no rebanho, após anos de liquidação de matrizes devido a problemas econômicos, levou ao aumento nas importações. A União Européia também é um grande importador, e a perspectiva de decréscimo na produção de carne, nos países desse bloco, sinaliza o incremento das importações, especialmente dos países do Mercosul. ${ }^{11}$

Em 2004, o consumo mundial de carne bovina foi cerca de 50 milhões, de acordo com dados do USDA. O maior mercado consumidor foi o dos Estados Unidos, que consumiram 12,6 milhões de toneladas, além do Brasil, China, Argentina, Rússia e México, que consumiram acima de 2 milhões de toneladas. Outro mercado importante foi o da União Européia, que consumiu 8,3 milhões de toneladas em 2004.

O consumo de carne bovina no mundo tem se mantido relativamente estável, nos últimos anos, apesar do declínio da demanda dos países europeus, devido à maior preocupação com saúde e segurança alimentar. A relativa estabilidade do comportamento do consumo mundial pode ser atribuída ao contínuo aumento na demanda dos países em crescimento, o que compensa o declínio da procura do produto pelos países desenvolvidos.

${ }_{11}$ WORLD beef overview. Disponível em: <http://www.fas.usda.gov>. Acesso em: maio 2005. 


\section{Metodologia}

Para atender ao objetivo de analisar o comportamento das exportações de carne bovina do Brasil diante dos seus principais concorrentes no mercado internacional, foram coletados dados sobre exportações e importações mundiais de carne bovina, nos anos de 1995 a 2003. Os dados coletados são referentes à carne bovina in natura, que corresponde a cerca de $90 \%$ do total das exportações mundiais do produto.

As informações foram obtidas no banco de dados COMTRADE, das Nações Unidas. Foram selecionados os maiores importadores de carne bovina in natura, quais sejam, Canadá, Coréia do Sul, França, Holanda, Japão, México, Reino Unido, Rússia e outros, que representam os demais importadores.

Este trabalho compara o desempenho do Brasil com o de seus principais competidores no mercado internacional de carne bovina. Os principais concorrentes, identificados durante a pesquisa, são Argentina, Austrália e Estados Unidos.

\subsection{O modelo Constant-Market-Share (CMS)}

O modelo CMS permite determinar os fatores que influenciam o desempenho das exportações de um país, ao longo dos anos. Esse tipo de análise foi aplicado, inicialmente, por Tyszynski, citado por Leamer e Stern (1970), para estudar as mudanças no market-share de países exportadores de bens manufaturados, de 1899 a 1950.

Este método foi utilizado por Rigaux (1971) na análise das exportações de trigo do Canadá, nos períodos de 1963-1964 a 1967-1968. O estudo de Sprott (1972) aplicou o CMS para verificar o comportamento das exportações de trigo da Austrália, nos períodos de 1950-1951 e 19691970. 
Lenilma Vera Nunes Machado, Mário Miguel Amin,

Fátima Marília Andrade de Carvalho \& Antônio Cordeiro de Santana

No Brasil, vários estudos aplicaram o CMS para avaliar a performance das exportações de produtos agrícolas e manufaturados, como os de Aguiar et al. (1979), para café em grão; Amin (1985), cacau em amêndoas; Carvalho (1995), complexo agroindustrial; Burnquist (1999), açúcar; Almeida (2003), soja em grão, entre outros.

Pelo método CMS, o crescimento favorável ou desfavorável do setor exportador é atribuído à estrutura das exportações do país e à sua competitividade. A principal vantagem deste método é permitir a análise, por componentes e pelo comportamento, do produto no mercado de destino.

Leamer e Stern (1970) partiram do princípio de que a demanda de um país importador é determinada pela relação de preços entre dois países exportadores e competidores no mercado internacional, representada por

$$
\frac{\mathrm{q}_{1}}{\mathrm{q}_{2}}=f\left(\frac{p_{1}}{p_{2}}\right)
$$

A equação (1) consiste na própria relação básica da elasticidade de substituição, em que $\mathrm{q}_{1}$ e $\mathrm{q}_{2}$ são quantidades vendidas pelos ofertantes e $\mathrm{p}_{1}$ e $\mathrm{p}_{2}$, respectivos preços. Multiplicando-se a equação acima por $\mathrm{p}_{1} / \mathrm{p}_{2}$, tem-se:

$$
\frac{p_{1} q_{1}}{p_{2} q_{2}}=\frac{\mathrm{p}_{1}}{\mathrm{p}_{2}} \times f\left(\frac{\mathrm{p}_{1}}{\mathrm{p}_{2}}\right)
$$

Rearranjando os termos: 


$$
\begin{aligned}
\frac{p_{1} q_{1}}{p_{1} q_{1}+p_{2} q_{2}} & =\left(1+\frac{p_{2} q_{2}}{p_{1} q_{1}}\right)^{-1} \\
& =\left\{1+\left[\frac{p_{1} f\left(p_{1} / p_{2}\right)}{p_{2}}\right]^{-1}\right\}^{-1} \\
& =g\left(\frac{p_{1}}{p_{2}}\right)
\end{aligned}
$$

A equação (3) indica que o market-share do país permanece constante, a não ser que a relação de preços $\left(\mathrm{p}_{1} / \mathrm{p}_{2}\right)$ mude. Caso o país não mantenha sua parcela no mercado mundial, o termo poderá ser negativo e indicará que os preços estão subindo mais rapidamente para o país em questão, em relação ao dos competidores.

Na formulação específica do modelo CMS, considera-se como variável básica o valor das exportações. Primeiro, consideram-se exportações não-diferenciadas por mercadorias e regiões, de modo que se tem a seguinte identidade:

$$
\mathrm{V}^{\prime} . .-\mathrm{V} . . \equiv \mathrm{rV}+\left(\mathrm{V}^{\prime} . .-\mathrm{V} . .-\mathrm{rV} . .\right)
$$

(a)

(b)

em que V.. é valor total das exportações do país A, no período 1; V', valor total das exportações do país A, no período 2 ; e r, aumento percentual das exportações mundiais, do período 1 para o período 2 . 
Lenilma Vera Nunes Machado, Mário Miguel Amin,

Fátima Marília Andrade de Carvalho \& Antônio Cordeiro de Santana

A identidade (4) mostra que a variação das exportações do país A, de um período a outro, está associada ao crescimento das exportações mundiais (a) e a um efeito residual atribuído à competitividade (b).

Considerando que as exportações são compostas por um conjunto diverso de mercadorias, tem-se, para a i-ésima mercadoria, a seguinte expressão:

$V^{\prime}{ }_{i} \cdot-V_{i} \equiv r_{i} V_{i} \cdot+\left(V^{\prime}{ }_{i} \cdot-V i \cdot-r_{i} V i.\right)$

A expressão (5) pode ser agrupada em

$$
V^{\prime} . .-V_{. .} \equiv(r V . .)+\sum_{i}\left(r_{i}-r\right) V_{i} \cdot+\sum_{i}\left(V_{i}^{\prime} \cdot .-V_{i} \cdot-r_{i} V_{i} \cdot\right)
$$

(a)

(b)

(c)

A equação (6) indica que o crescimento das exportações é atribuído: (a) ao crescimento geral das exportações mundiais; (b) à composição de bens das exportações do país A, no período 1; e (c) ao efeito residual resultante da diferença entre a variação efetiva e a variação esperada nas exportações de cada grupo de bens.

Ao considerar a diferenciação das exportações por destino e por tipo de mercadoria, chega-se ao modelo CMS para um tipo particular de mercadoria e região particular de destino, especificado a seguir:

$$
V_{i j}^{\prime}-V_{i j} \equiv r_{i j} V_{i j}+\left(V_{i j}^{\prime}-V_{i j}-r_{i j} V_{i j}\right)
$$

em que $\mathrm{V}_{\mathrm{ij}}$ é valor das exportações da mercadoria $\mathrm{i}$, do país A para o país j, período $1 ; \mathrm{V}_{\mathrm{ij}}$, valor das exportações da mercadoria i, do país $\mathrm{A}$ para o país $\mathrm{j}$, período $2 ; \mathrm{r}_{\mathrm{ij}}$, incremento percentual nas exportações mundiais da mercadoria i para o país j, do período 1 para o período 2 . 
Agrupando a equação (7), tem-se:

$V^{\prime} . .-V . . \equiv r V . .+\sum_{i}\left(r_{i}-r\right) V_{i} \cdot+\sum_{i} \sum_{j}\left(r_{i j}-r_{i}\right) V_{i j}+\sum_{i} \sum_{j}\left(V_{i j}^{\prime}-V_{i j}-r_{i j} V_{i j}\right)$.

(a) (b)

(c)

(d)

A identidade (8) permite decompor a taxa de crescimento das exportações do país A em quatro efeitos:

(a) Efeito crescimento do comércio mundial: incremento observado se as exportações do país A tiverem crescido à mesma taxa do comércio mundial;

(b) Efeito composição da pauta: mudanças na estrutura da pauta com concentração em mercadorias com crescimento de demanda mais ou menos acelerado;

(c) Efeito destino das exportações: mudanças decorrentes das exportações de mercadorias para mercados de crescimento mais ou menos dinâmicos; e

(d) Efeito competitividade: calculado como efeito residual resultante da diferença entre crescimento das exportações e crescimento efetivo das exportações.

O efeito crescimento do comércio mundial (a) não requer comentários, porém os demais necessitam de uma interpretação adicional. $\mathrm{O}$ efeito composição da pauta (b) indica que, se as exportações mundiais do produto i aumentarem mais que a média mundial para todas as mercadorias exportadas, o termo $\left(r_{i}-r\right)$ será positivo. Esse efeito será positivo, se as exportações do país A estiverem concentradas em mercados com crescimento acelerado, e negativo, se estiverem concentradas em mercados com baixo crescimento. Cabe destacar que o método CMS, quando aplicado a uma única mercadoria, torna nulo o efeito composição da pauta, tendo em vista que o termo da equação relativo a esse efeito é eliminado. 
Lenilma Vera Nunes Machado, Mário Miguel Amin,

Fátima Marília Andrade de Carvalho \& Antônio Cordeiro de Santana

O efeito destino das exportações (c) tem interpretação análoga ao efeito composição da pauta; será positivo, se o país A tiver concentrado suas exportações em mercados com maior dinamismo, e negativo, se concentrado em regiões menos dinâmicas.

O efeito competitividade (d), quando negativo, indicará o fracasso do país em manter a sua parcela no mercado mundial. Este efeito pode estar associado aos preços relativos, assim como será influenciado por um conjunto de fatores que poderão afetar a atratividade relativa das exportações de dado país. Tais fatores incluem "mudanças tecnológicas, medidas de apoio ao setor exportador, melhoria nas condições de financiamento, melhoria na eficiência de marketing, existência de taxas diferenciadas de inflação entre os países, entre outros" (Carvalho, 2004, p. 226).

A aplicação do modelo CMS é realizada entre pontos discretos no tempo, por isso, há necessidade de se fixarem períodos de análise. Para Carvalho (1995), a divisão em períodos mais curtos permite identificar, com mais precisão, as mudanças que ocorreram na estrutura das exportações, entre o início e o fim do período de estudo.

São considerados três subperíodos, cada um correspondente à média de três anos, como forma de minimizar um efeito de um ano até o pico. Foram selecionados os seguintes períodos:

a) 1995/96/97 - primeiro período: representa a fase de estabilização da economia brasileira e seus impactos no setor exportador;

b) 1998/99/00 - segundo período: refere-se à etapa de alavancagem das exportações brasileiras de carne bovina;

c) 2001/02/03 - terceiro período: relativo aos anos mais recentes de crescimento das exportações brasileiras de carne bovina. 


\section{Resultados e discussão}

Os resultados da decomposição nos efeitos crescimento do comércio mundial, destino das exportações e competitividade são apresentados no Quadro 2. O efeito composição da pauta não pôde ser estimado, conforme explicado na metodologia.

Observa-se que o desempenho desfavorável das exportações de carne bovina da Argentina, nos três períodos analisados, está associado aos efeitos negativos de competitividade e destino das exportações, os quais contribuíram para redução no volume exportado. A constante participação negativa do efeito destino das exportações indica que o país concentrou suas vendas em mercados menos dinâmicos, em vez de destiná-las a países com crescimento nas importações acima da média mundial.

O efeito competitividade negativo, em todos os períodos analisados, mostra que a Argentina foi pouco competitiva no mercado internacional. Esse comportamento indica que a parcela relativa da Argentina em determinados mercados deve ter diminuído drasticamente, a ponto de prejudicar o desempenho global das exportações.

O resultado positivo do efeito crescimento do mercado, em todos os períodos analisados, demonstra que, apesar de mostrar decréscimo em suas exportações globais, a Argentina soube aproveitar a expansão do mercado mundial. A participação positiva desse efeito colaborou para diminuir as perdas geradas pelos outros efeitos.

As exportações da Argentina apresentaram sinais de recuperação em 2004, o que sinalizou melhoria dos indicadores. Neste ano, o país exportou 478 mil toneladas de carne bovina; tornou-se o terceiro maior exportador do mundo; voltou a comercializar arne in natura com os parceiros tradicionais, principalmente a União Européia, e conquistou novos mercados, para compensar a redução em outros, como Canadá, Estados Unidos e México. 
Lenilma Vera Nunes Machado, Mário Miguel Amin,

Fátima Marília Andrade de Carvalho \& Antônio Cordeiro de Santana

Quadro 2 - Fontes de crescimento das exportações da Argentina, Austrália, Estados Unidos e Brasil, 1995-2003

\begin{tabular}{|c|c|c|c|}
\hline & Período II - 1998-2000 / & Período III - 2001-2003 / & Período III - 2001-2003/ \\
\hline Fontes de Crescimento & Período I - 1995-1997 & Período I - 1995-1997 & Período II - 1998-2000 \\
\hline \multicolumn{4}{|l|}{ ARGENTINA } \\
\hline - Efeito Crescimento do Comércio Mundial & $26,21 \%$ & $37,78 \%$ & $51,26 \%$ \\
\hline - Efeito Destino das Exportações & $-19,32 \%$ & $-18,40 \%$ & $-2,93 \%$ \\
\hline - Efeito Competitividade & $-106,89 \%$ & $-119,38 \%$ & $-148,36 \%$ \\
\hline \multicolumn{4}{|l|}{ AUSTRÁLIA } \\
\hline - Efeito Crescimento do Comércio Mundial & $51,72 \%$ & $86,52 \%$ & $472,16 \%$ \\
\hline - Efeito Destino das Exportações & $-26,25 \%$ & $-55,07 \%$ & $-311,47 \%$ \\
\hline - Efeito Competitividade & $74,53 \%$ & $68,54 \%$ & $-60,68 \%$ \\
\hline \multicolumn{4}{|l|}{ ESTADOS UNIDOS } \\
\hline - Efeito Crescimento do Comércio Mundial & $29,68 \%$ & $47,70 \%$ & $204,43 \%$ \\
\hline - Efeito Destino das Exportações & $65,46 \%$ & $81,34 \%$ & $152,75 \%$ \\
\hline - Efeito Competitividade & $4,86 \%$ & $-29,04 \%$ & $-257,18 \%$ \\
\hline \multicolumn{4}{|l|}{ BRASIL } \\
\hline - Efeito Crescimento do Comércio Mundial & $3,87 \%$ & $1,57 \%$ & $2,62 \%$ \\
\hline - $\quad$ Efeito Destino das Exportações & $0,48 \%$ & $1,27 \%$ & $3,06 \%$ \\
\hline - Efeito Competitividade & $95,65 \%$ & $97,16 \%$ & $94,32 \%$ \\
\hline
\end{tabular}

Nota: As fontes de crescimento das exportações foram calculadas para cada período em relação ao período-base. Assim, calcularam-se os resultados para os períodos II-19982000 e III-2001-2003, em relação ao período I-1995-1997, e para o período III-20012003, em relação ao período II-1998-2000.

Fonte: dados da pesquisa.

No caso da Austrália, o efeito crescimento do comércio mundial contribuiu para impulsionar as exportações, porém o efeito destino das exportações colaborou para reduzi-las. A participação negativa deste efeito indica que o país concentrou suas exportações em mercados com pouco dinamismo da demanda. Esse comportamento atingiu seu nível mais crítico no terceiro período, 2001-2003, em relação ao período-base 1998-2000, quando o efeito destino das exportações foi negativo, com $311 \%$. As causas da participação negativa desse efeito estão relacionadas com problemas de ordem estrutural.

O efeito competitividade positivo, nos períodos II e III em relação ao período I-1995-1997, contribuiu para aumentar as exportações totais, mas o resultado negativo no período III, em relação ao período-base 19982000, demonstra que a Austrália perdeu posição para outros competidores 
no mercado internacional. A pouca competitividade da Austrália, nesse período, possivelmente esteja relacionada com a queda em suas parcelas relativas nos principais mercados importadores.

A Austrália aumentou suas exportações para a Coréia do Sul e para o Japão em 2004, devido à suspensão das importações de carne bovina americana por esses países, após a descoberta de um caso de vaca louca nos Estados Unidos. As vendas para Japão e Coréia do Sul aumentaram $31 \%$ e $54 \%$, respectivamente, conforme informações do COMTRADE. No entanto, ao aumentar as exportações para esses países, a Austrália teve fatias em mercados secundários conquistadas pelo Brasil e pela Argentina.

O desempenho favorável das exportações dos Estados Unidos está associado à alta participação positiva dos efeitos estruturais de crescimento do comércio mundial e destino das exportações, o que indica que o país foi agressivo em suas políticas de comercialização. O comportamento do efeito competitividade, pouco expressivo no período II-1998-2000 em relação ao base 1995-1997, mostrou-se negativo no período III-2001-2003, independente do período-base utilizado. A influência negativa do efeito competitividade indica que os Estados Unidos não conseguiram compensar a redução nas parcelas relativas em certos mercados com o aumento em outros mercados importadores. As perdas de parcelas relativas mais significativas ocorreram nos mercados do Canadá, México e Japão.

Os Estados Unidos apresentaram perda de competitividade devido à queda abrupta de suas exportações em 2004. Os grandes importadores restringiram as importações de carne americana logo após o anúncio de um caso de vaca louca no país, assim como Canadá e México, que também restringiram as importações de carne americana em 2004, mas relaxaram o embargo no mesmo ano, excluindo apenas a carne de animais abatidos acima de 30 meses de idade. 
Lenilma Vera Nunes Machado, Mário Miguel Amin,

Fátima Marília Andrade de Carvalho \& Antônio Cordeiro de Santana

Os resultados mostram que o Brasil conseguiu manter a sua posição competitiva no mercado internacional. O efeito competitividade foi o principal responsável pelo aumento das exportações de carne bovina in natura, ao impulsionar o crescimento das vendas, de forma que o país conseguiu elevar o seu market-share de $0,9 \%$, no período I, para 8,3\%, no período III. Os efeitos estruturais de crescimento do mercado mundial e destino das exportações contribuíram, em menor porcentagem, para o incremento observado.

A competitividade das exportações brasileiras de carne bovina in natura pode estar relacionada com um conjunto de fatores. Os investimentos em tecnologia permitiram melhorar os índices da pecuária de corte, visto que contribuíram para o aumento do rebanho e da produção de carne para atender à demanda externa crescente do produto brasileiro. A sanidade do rebanho foi fator fundamental para o crescimento das exportações, uma vez que a ocorrência de doenças no rebanho dos principais exportadores levou os países importadores a procurar novos fornecedores; assim, o Brasil ampliou suas vendas para a Europa e conquistou mercados no Oriente Médio. A desvalorização cambial contribuiu para impulsionar as exportações, ao tornar os preços da carne bovina mais competitivos no mercado internacional. Além disso, as ações de marketing e promoção do produto no mercado externo também podem ter estimulado a expansão das vendas.

\section{Conclusões}

A aplicação do modelo de comércio internacional CMS mostra que o Brasil conseguiu manter a sua posição competitiva no mercado internacional diante dos seus principais concorrentes. Embora este método não permita determinar os fatores responsáveis pelos resultados, podemse apontar algumas possíveis causas do desempenho favorável das exportações brasileiras. A garantia de sanidade do rebanho, a melhoria nos índices da pecuária de corte, os avanços na genética e as estratégias para promoção do produto brasileiro no mercado externo converteram- 
se em vantagens que permitiram ao país ser mais competitivo no mercado internacional e, conseqüentemente, expandir suas exportações.

Outro ponto importante se relaciona com a capacidade de expansão do rebanho bovino para atender à demanda externa. $\mathrm{O}$ Brasil tem condições de expandir a produção de carne para suprir o mercado externo devido à expansão do rebanho nos últimos anos, enquanto muitos produtores mundiais enfrentam dificuldades para aumentar a oferta.

Os principais concorrentes, no mercado internacional, foram menos competitivos que o Brasil em determinados períodos. As exportações da Austrália cresceram tanto em decorrência do crescimento das exportações mundiais como da competitividade, com exceção do último período, 20012003, quando o resultado foi desfavorável para este efeito. A retomada das exportações de carne bovina pelos Estados Unidos, nos próximos anos, pode afetar a rentabilidade da Austrália, que aumentou as vendas para os principais mercados consumidores em virtude das restrições à comercialização da carne americana.

Nos Estados Unidos, o crescimento das exportações esteve associado ao êxito de suas políticas de comercialização, entretanto, a queda nas exportações afetou o desempenho do país. Quanto à Argentina, a deterioração das suas exportações resultou na perda de posição competitiva no mercado internacional, porém a recuperação das vendas, em 2004, sinalizou melhoria dos indicadores.

A consolidação do crescimento das exportações de carne bovina no Brasil depende do fato de o país conseguir manter as vantagens conquistadas para sustentar a sua posição competitiva e explorar novas oportunidades de negócios. 
Lenilma Vera Nunes Machado, Mário Miguel Amin,

Fátima Marília Andrade de Carvalho \& Antônio Cordeiro de Santana

\section{Referências}

AGUIAR, L. A. et al. Análise fracional do mercado externo de café. Experientiae, Viçosa, v. 25, n. 6, p. 111-129, jun. 1979.

ALMEIDA, A. et al. Padrão de comércio internacional da soja em grão: Brasil vis-à-vis Argentina e Estados Unidos. In: CONGRESSO DE ECONOMIA E SOCIOLOGIA RURAL, 41. 2003, Juiz de Fora. Anais... Juiz de Fora, 2003. 1 CD-ROM.

AMIN, M. M. Análise do mercado mundial de exportação de cacau, 1962-81: uma aplicação de Market-Share analysis. Belém: CEPLAC, $1985.57 \mathrm{p}$.

ANUÁRIO DA PECUÁRIA BRASILEIRA. São Paulo: FNP Consultoria \& Agroinformativos, 1998-2005. 8 v.

BURNQUIST, H. L.; MIRANDA, S. H. G. de. Desempenho recente das exportações brasileiras de açúcar: uma abordagem de "Market Share" constante. Revista da Sociedade Brasileira de Economia e Sociologia Rural, Brasília, DF, v. 37, n. 3, p. 69-89, 1999.

CARVAlHO, F. M. A. de. Método "Constant Market Share" (CMS). In: SANTOS, M. L. de; VIEIRA, W. da C. (Ed.). Métodos quantitativos em Economia. Viçosa: UFV, 2004. p. 225-241.

Comportamento das exportações brasileiras e a dinâmica do complexo agroindustrial. 1995. 126 f. Tese (Doutorado em Economia) - Escola Superior de Agricultura Luiz de Queiroz, Piracicaba, 1995.

DICK, J. H.; NELSON, K. E. Structure of the global markets for meat. Agriculture Information Bulletin, n. 785, set. 2003. Disponível em: $<$ http://www.ers.usda.gov>. Acesso em: maio 2004. 
GASQUES, J. G.; BASTOS, E.T. Terra: compare os preços entre o Brasil e os Estados Unidos. Agroanalysis, Rio de Janeiro, v. 25, n. 6, p. 18-20, jun. 2005.

LEAMER, E. E.; STERN, R. M. Quantitative internacional economics. Boston, Massachusetts: Allyn and Bacon, 1970.

MARGARIDO, M. A. A questão cambial e a balança comercial no Brasil pós-Plano Real. Informações Econômicas, São Paulo, v. 31, n. 11, p. 55-64, nov. 2001.

MINISTÉRIO DO DESENVOLVIMENTO E COMÉRCIO EXTERIOR. Sistema Aliceweb. 1990-92 [banco de dados]. Disponível em: <http://www.desenvolvimento.gov.br>. Acesso em: ago. 2005.

MUSTEFAGA, P. S. Bons resultados. Agroanalysis, Rio de Janeiro, v. 22, n. 10, p. 32-35, dez. 2002/jan. 2003.

NEHMI FILHO, V. B. Para onde caminha a pecuária brasileira. Anualpec, São Paulo, p. 14-23, 2005.

RIGAUX, L. R. Market Share analysis aplied to canadian wheat exports. Canadian Journal of Agricultural Economics, Orleans, v. 19, n. 1, p. 22-34, July 1971.

SABELLA, J. Boi verde 'made in Brasil'. Agroanalysis, Rio de Janeiro, v. 24, n. 11, p. 28-29, nov. 2004.

SPROTT, D. C. Market Share analysis of Australian wheat exports between 1950-51 and 1969-70. The Wheat Situation, Bureau of Agricultural Economics, n. 35, p.11-16, July 1972.

TORRES JÚNIOR et al. A evolução da pecuária de corte no Brasil. Agroanalysis, Rio de Janeiro, v. 25, n. 6, p. 40-42, jun. 2004.

UNITED NATIONS. Commodity Trade Statistics Database. 1995- 
Lenilma Vera Nunes Machado, Mário Miguel Amin,

Fátima Marília Andrade de Carvalho \& Antônio Cordeiro de Santana

2003. [banco de dados]. Disponível em: <http://unstats.un.org/unsd/ comtrade>. Acesso em: jan. 2005.

UNITED STATES DEPARTMENT OF AGRICULTURE. Informações sobre produção, exportações, importações e consumo de carne bovina. 1995-2005. [banco de dados] Disponível em: 〈http://www.fas.usda.gov〉. Acesso em: ago. 2005.

WORLD beef \& cattle trade: evolving \& expanding. Economic Research Service, Agricultural Outlook, p. 6-10, dec. 1997. Disponível em: <http:/ /www.ers.usda.gov>. Acesso em: maio 2004.

WORLD beef overview. Disponível em: 〈http://www.fas.usda.gov>. Acesso em: maio 2005.

Abstract - The study analyzes the behavior of the Brazilian's beef exports, in natura, during the 1995 to 2003 period. It shows that the substantial increase in exports made the country one of the leading beef exporters and tries to identify the factors that contributed for this growth. The methodological procedures involve the application of the Constant-Market-Share model to identify the sources of growth of the exports through the world trade growth effect, origin of exports effect and competitive effect. The composition effect was not estimated given the fact that the model was applied to only one product. The results show that the competitive and structural effects gave a significant increase to the Brazilian's exports. The study shows, also, that Brazil increased its market share due the several factors that contributed to an expansion in its exports through new world markets.

Keywords: Brazilian's beef exports, Constant-Market-Share, competitive and structural effects. 
REVISTA DE ECONOMIA E AGRONEGÓCIO, VOL.4, $N^{\circ} 2$ 